\title{
APLICAÇÃO DE FERRAMENTAS ESTATÍSTICAS NA ANÁLISE DA PLUVIOMETRIA NO MUNICÍPIO DE SÃO PAULO
}

\author{
Ronaldo Sérgio Vasques ${ }^{1}$ \\ Fabrisia de Moraes Alves da Silva ${ }^{2}$ \\ Eltiza Rondino Vasques ${ }^{3}$ \\ Paulo Roxo Barja ${ }^{4}$
}

Resumo: O índice pluviométrico indica a quantidade de chuva por metro quadrado em determinado local e em determinado período. O objetivo deste trabalho é comparar, por meio de análise estatística, os dados pluviométricos obtidos nos meses de Junho de 2015 e Junho de 2016, verificando os possíveis motivos que causam a diferença no volume de precipitações, de um ano para outro. $A$ metodologia incluiu a pesquisa dos dados de pluviometria no município de São Paulo e o cálculo de parâmetros estatísticos como média aritmética, desvio padrão e coeficiente de variação, ilustrando uma aplicação prática dos conceitos aprendidos em sala de aula.

Palavras-chave: Clima; Estatística; Pluviometria; São Paulo.

\footnotetext{
${ }_{1}^{1}$ Bioengenharia/Universidade do Vale do Paraíba, Brasil. E-mail: rsvasques@uol.com.br.

${ }^{2}$ Bioengenharia/Universidade do Vale do Paraíba, Brasil. E-mail: fab.masilva@gmail.com.

${ }^{3}$ Geografia/Universidade de São Paulo, Brasil. E-mail: eltiza@gmail.com.

${ }^{4}$ Bioengenharia/Universidade do Vale do Paraíba, Brasil. E-mail: barja@univap.br.
} 